\title{
Bus priorities and their effects on local trade
}

\author{
S. Ward \\ Faber Maunsell, UK
}

\begin{abstract}
Bus priorities are often favoured by transport authorities in urban areas as a costeffective means of reducing congestion and reliance on the car through promoting more sustainable travel. However, where their introduction involves reduction in the availability of on-street parking in local shopping areas, opposition frequently arises from retailers concerned over the impact on car-borne trade. This paper reviews the links between transport policy, parking and the economy of local trade and considers the effects new bus priorities may have. There is strong evidence to suggest that car-borne and bus-borne shoppers are of fairly similar importance to trade, contrary to many retailers perceptions; furthermore the local nature of shopping in these areas and the consequent importance of the walking environment appears to be greatly underestimated.

Keywords: bus priorities, retail, local shopping, parking enforcement.
\end{abstract}

\section{Introduction}

The introduction of bus priorities has many attractions for those charged with promoting more sustainable travel: flexible, more economical and more easily integrated than other forms of public transport they are seen as a relatively lowcost, high-profile way of attracting more passengers in an otherwise declining bus market. In recent years the UK bus industry has been forced to adapt to this shrinking market through forming partnerships with local authorities in their efforts to mitigate the effects of congestion on services in urban areas while developing more flexible and responsive services in rural districts such as community transport initiatives. 


\subsection{Policy background to Bristol Showcase}

In the city of Bristol, the local authority demonstrated growth in patronage on several park and ride routes through the introduction of bus priorities in the early 1990s. Encouraged by these achievements, but facing high levels of congestion and dissatisfaction with public transport in the city, the council together with the dominant local bus operator First Bristol developed the concept of 'Showcase' an ambitious programme of 'whole corridor' improvements to bus routes. This was to incorporate upgrades to infrastructure such as new buses, real-time information, bus lanes and junction signal priority as well as new service quality agreements. The first scheme was proposed on a heavily congested corridor linking the residential areas of urban deprivation of Hartcliffe and Southmead in the north and south of the city with the city centre. This corridor also passed through the local shopping area of Bishopston, on the northern edge of the city centre.

\subsection{Opposition to Showcase}

During the consultation period for the proposed route, vocal opposition to the scheme began to emerge, focused on the busy shops in Bishopston. Retailers and other local businesses expressed concerns that the loss of on-street parking required for the construction of a new bus lane would adversely affect trade. The local traders association argued that were parking to be made more difficult, potential customers would simply drive to competing larger centres including out-of-town sites which provided free and ample parking.

\section{Mode of travel and local shopping}

There are numerous studies investigating modal choice in travel to local shops. Hathaway's study of a similar shopping area in Bristol [1] found that $89 \%$ of residents visited the shops on foot, with only $9 \%$ arriving by car. A study of the smaller shopping centres in London by Transport for London [2] also showed that the majority of shoppers visited on foot $(62 \%)$ compared with just $18 \%$ by bus and $11 \%$ by car. Additionally it was found that the total spent by those arriving on foot accounted for significantly more than those arriving by car or bus, primarily due to their greater number and frequency of visits to the area. TfL's subsequent study on town centres and local buses [3] suggested that trade in these higher-order centres was still primarily local, with those walking to shops remaining the largest group travel whose spend constituted the greatest share.

The opposition to Showcase priorities due to its perceived effect on parking in Bishopston, Bristol was the subject of a study by cycling charity Sustrans. It found that $40 \%$ of customers travelled less than 10 minutes walking distance from the shops, perhaps indicating why the majority (54\%) arrived on foot, with $20 \%$ arriving by car and $14 \%$ by bus. 


\subsection{Summary}

It is clear that the most significant mode of travel to local shops is walking, and that its market covers a relatively small area. In comparing bus with car travel to local shops, the London studies indicated that the bus may be more significant, although in the more car-dominated market outside London the situation is not clear.

\section{Traders perceptions of customer travel}

The studies discussed in the section above also provide us with an understanding of local traders' perceptions of their customers' travel habits as well as their transport priorities for their area. Hathaway's study [1] showed that the travel patterns of traders and their customers were quite different; traders were over seven times more likely to drive to use a car to access district centres than their customers were in travelling there to shop; consequently their identification of improvements in transport to the area primarily consisted of measures to improve car access, such as construction of new parking areas and resisting proposals for pedestrianisation.

Sustrans' study of the Showcase route in Bishopston, Bristol [4] suggested that this pattern may be evident here; when surveyed, traders overestimated the number of people travelling by car by $95 \%$ and underestimated the number travelling on foot by $22 \%$. It would appear that they believed their customers travelled further to shops than was the case.

\subsection{Effects of traders perceptions of customer travel}

This mis-conception of the modal share of their customers appears to influence local traders' attitudes to transport priorities in their area.

The study of town centres by TfL [3] gathered the opinions of town centre managers and key business stakeholders who expressed concern that further measures to increase bus use, such as extended bus stops, should not come at the expense of discouraging car use or parking. This is in contrast with the opinions of visitors to the area who considered priorities for the area to be improvements to the pedestrian environment such as cleaner streets and a reduction in traffic. A similar effect may be occurring at other retail locations where measures to improve the pedestrian environment require limitations on car access; in Henley in Oxfordshire, a minor pedestrianisation scheme was reduced in scale following complaints by shopkeepers that trade would be affected.

The Sustrans study [4] showed that traders' two highest priorities for changes to traffic management in Bishopston were an increase in car parking (38\%) and removal of the bus priorities (27\%). Indeed $40 \%$ of traders felt that Showcase bus priorities had a negative effect on the area, compared to just $6 \%$ considering this measure positive. The majority of customers felt that Showcase had neither a positive nor a negative effect on the area. 


\subsection{Summary}

The above evidence suggests that traders' travel patterns to local shopping areas in which they work are significantly different from those who visit the area to shop. The relatively higher reliance by local traders on the car for travel appears to manifest itself as a resistance to measures to improve travel by other modes that may affect car access.

\section{The local retail market in the UK}

The small retail business sector has been in chronic decline for many years. The Department for Trade and Industry [5] report that the number of retail businesses declined by one fifth while turnover nearly doubled in the ten years to 1994 , suggesting substantial consolidation into larger operations. The government calculates [6] that the growth in large edge- and out-of-town superstores has led to a decline in trade of principal food retailers in district centres of between 13 and $50 \%$. The market share of multiples has doubled, while that of independents has halved [5]. Where supermarkets have ventured into the traditional high street, they can compete not only with food retailers but with other businesses by incorporating cash points, post offices, pharmacies, dry-cleaners and restaurants [6]. These smaller, multi-purpose, flexible-format supermarkets may be indicative of a change in retailing in the UK; demographic and social changes such as the tendency for more people to live alone and have less time for shopping mean that more people are shopping on their own, closer to home and more frequently than before [7].

\subsection{Bus priorities and shopping destination choice}

Additional bus services that were not part of the Showcase programme are likely to have benefited from the introduction of the bus priorities on the route. These services include those that connect the Bishopston area to additional shopping centres that could compete with it. To what extent such services facilitate travel to local shops, compared with the potential effect of encouraging travel to larger centres with a wider retail offer in other locations is not known.

\subsection{Conclusions}

Bishopston could be characterised as a very traditional high street; it contains a relatively high proportion of independent shops, including a large number of food retailers and thus has the potential to adapt well to these recent changes in shopper behaviour. To what extent the opening of a second supermarket in the area is likely to enhance overall vitality or compete with trade is not clear.

\section{$5 \quad$ Effects on car parking}

As indicated above, the most contentious issue related to Showcase for local traders was the potential effects on trade of the reduction in parking. In 
Bishopston, no loading is permitted on the road for $1 \frac{1}{2}$ hours of the working day due to the operation of the bus lane. Traders' views on parking are often influenced by what they see as a biased policy of the local authority fining customers who spend too long loading their vehicles outside their shops while those visiting competing out-of-town centres are offered free and unrestricted parking [8].

In response to these concerns over parking the council made several concessions; additional parking spaces were introduced in neighbouring streets (albeit in less convenient locations than the ones they replaced directly outside the shops) together with a 'shoppers car park' where up to three hours free parking was permitted.

\subsection{Car parking study}

Studies were conducted to determine how the demand for parking was being affected through the new parking enforcement conditions introduced with Showcase [9]. These demonstrate that parking enforcement through traffic wardens was of limited effect in removing unauthorised vehicles from the bus lane. During the periods in the day when loading was prohibited, approximately $16 \%$ of the total parking spaces in the bus lane remained occupied. As a consequence, no buses were observed using the bus lane at these times, rendering the bus priority lane ineffective. A 'wave' of parking enforcement was perceived, which was exploited by some drivers who upon observing traffic wardens approaching drove off and re-parked further along the road.

Nevertheless it is concluded from the data that a substantial number of vehicles - in excess of 100 - are being inhibited from parking during the prohibited loading period. Demand also greatly outstrips supply in the shoppers' car park, as $30 \%$ of vehicles entering were unable to find a space to park. Since this facility only offers approximately 20 spaces it appears to play a minor role in replacing the 'lost' on-street spaces. However, from observations at similar shopping centres elsewhere, including Edmonton Angel and Canning Town in London, on-street loading was still observed in the bus lane despite ample free parking situated a few metres from the shops [9].

\subsection{Shopper attitudes to parking enforcement}

Car-borne shoppers were interviewed as part of this study for their opinions on parking enforcement [9]. Over half of shoppers stated that they were never concerned about receiving a fixed penalty parking ticket, with less than 5\% stating that they worried about this 'often'. However, $15 \%$ of car-borne shoppers stated that they avoid parking during the restricted period, and $9 \%$ stated that they come to the area less often. The Sustrans study [4] reported a larger number of car-borne customers (20\%) shop less often due to Showcase, although $23 \%$ of customers arriving by bus said they would use the area more and the majority said their use of the area remained the same. However, neither study is capable of determining the proportion of former visitors who no longer shop in the area due to the restrictions. 


\subsection{Summary}

It seems likely from the evidence above that the introduction of Showcase has had a negative effect at least on the convenience of parking in Bishopston. The introduction of new parking spaces at other locations may have offset the reduction of on-street spaces to some extent, although during the prohibited loading period this does not appear to cover the shortfall in supply. However when considering the ability of drivers to park in the area, the increase in supply of parking during the non-prohibited loading period due to the shoppers car park and additional nearby on-street spaces must also be taken into account.

\section{Conclusions}

\subsection{Modal contribution to trade}

The Bristol and London studies show that the most important mode for retail trade in district shopping centres is walking, since the total weekly spend of those travelling on foot is greater.

Evidence on the contribution to retail trade made by bus passengers versus those arriving by car is more mixed; in London, where the bus generally enjoys a higher status the contribution appears higher, whereas in Bristol it appears similar or slightly lower to car-borne trade. However, the two modes can frequently conflict, particularly where roads are attempting to serve both highfrequency public transport access and on-street parking. A compromise has been struck in Bristol whereby parking is allowed in the bus lane during the day and prohibited during the peak hours. But only a small number of vehicles parking during these hours are enough to prevent buses from using the lane - leading to a 'lose-lose' situation where the majority of drivers decide not to risk parking due to the restrictions, and buses gain no time savings from the priority scheme.

\subsection{The retail economy}

Recent changes to shopping patterns present opportunities for district centres, but restructuring of the retail sector is unlikely to favour independent traders. Supermarkets, having taken over much of the food retailing sector, are now growing the non-food and service areas of their business. Whereas before they competed principally with the food sector - leading to the disappearance of bakers, butchers and greengrocers - other independent shops can expect to face greater competition. This competition is increasingly being brought directly to District Centres with the advent of more flexible, smaller supermarket formats.

\subsection{Parking}

Parking control in Gloucester Road appears not to have been effective. Other local authorities, particularly in London, have used their decriminalised parking enforcement powers to introduce stricter enforcement through CCTV cameras on buses, together with high-profile information campaigns. 


\subsection{Traders' perceptions of customers' travel}

Traders and other key stakeholders often appear to misapprehend the importance of car borne travel to local shops. This may be based on the different travel patterns of those stakeholders. In addition, vehicles struggling to park outside a shop are a highly visible access problem; pedestrians struggling to find a safe place to cross the road, or simply having difficulties negotiating crowded and cluttered pavements are less so.

\subsection{Effect of showcase bus priorities on trade}

The question of whether the introduction of Showcase has deterred car-borne trade is difficult to answer, as those who no longer visit are not available to survey. However, there is no evidence to suggest that any significant reduction in the frequency of car-borne visits has occurred, at least by those who continue to visit the area. Car travel to the centre is predominantly local, suggesting that long-distance passing trade is less significant. The local nature of travel indicates both that the district centre is serving local needs and that many of these journeys could potentially be substituted for other forms of transport, particularly walking. However, these journeys could also consist of linked trips - hence more research in this area would be required.

In summary, the potential benefits of bus priority schemes on the economic vitality of local shops will only be realised where some level of consensus is achieved between those promoting bus priorities and traders who feel they depend on a convenient supply of parking, both for their customers and in order to enable deliveries to take place. It is important to ensure retailers have information on the relative contribution of walking, bus, car and other modes of travel to their trade. However, no amount of convenient parking alternatives appears to offer enough of a 'carrot' to ensure that bus priority lanes are kept free of parking - here the enforcement 'stick' needs to be employed to ensure that the benefits are maintained for buses so they can play their important role in the life of those centres. Additionally, local shops are likely to benefit if greater priority is given to the needs of pedestrians when designing bus priority schemes - the chance to make changes to the streetscape that will encourage more walking should form an integral part of area-wide access improvement schemes, for which traffic reduction, as well as more pedestrian facilities, is likely to play a role.

\section{References}

[1] Hathaway, T, Clifton Traffic And Parking Study, Severnside Research Unit: Bristol Polytechnic, 1992.

[2] Transport for London, London Bus Initiative Phase I Evaluation: Technical Report for Government Office London, TfL: London, 2004.

[3] Transport for London, Town Centres Survey: Final Report, TfL: London, 2005. 
102 Urban Transport XII: Urban Transport and the Environment in the 21st Century

[4] Sustrans, Real and Perceived Travel Behaviour in Neighbourhood Shopping Areas in Bristol: Final Report, Sustrans: Bristol, 2006.

[5] DTI, Competitive Analysis of the Retail Sector in the UK, Department for Trade \& Industry: London, 2003.

[6] DETR, The Impact of Large Foodstore Development on Market Towns and District Centres, Department of Environment, Transport and the Regions: London, 1998.

[7] LUMS, Retail Competition and Consumer Choice, Marketing Department, Lancaster University Management School: Lancaster, 2004.

[8] Blythman J, Shopped: The Shocking Power of British Supermarkets, Fourth Estate: London, pp7-8, 2004.

[9] Ward, 2004. MSc dissertation research by the author.

[10] Bristol City Council, Showcase Bus Route 76/77 - A38 Bus Priorities: Report of DETL, Bristol City Council: Bristol, 2003. 